\title{
Hipóteses ontogenéticas relativas à consciência moral: possibilidades em consciência histórica de jovens brasileiros
}

\author{
Ontogenetic hypotesis concerned \\ with moral consciousness: \\ possibilities in historical consciousness \\ of Brazilian youngs
}

\author{
Maria Auxiliadora Moreira dos Santos Schmidt ${ }^{1}$
}

\begin{abstract}
RESUMO
Segundo Rüsen (2010), diante de uma situação da vida prática, a tomada de decisões depende de valores e a consciência histórica é um pré-requisito necessário para a mediação entre valores e realidade. Isso porque ela funciona como um modo específico de orientação em situações práticas da vida no presente, porque une o passado ao presente, conferindo perspectivas de futuro à realidade em que se vive, moldando os valores morais a um "corpo temporal". A partir desses pressupostos, foi realizada uma investigação qualitativa (EISNER, 1998) em 60 jovens brasileiros (13 a 16 anos) de camadas populares, alunos de uma escola pública da cidade de Curitiba-PR. Solicitou-se uma narrativa a partir da seguinte questão: "Escreva para um jovem como você suas reflexões sobre o seguinte - $O$ altruísmo, o pensamento não efêmero e a diferença ainda têm lugar no mundo contemporâneo?". A escolha dessa questão justifica-se porque foi ela foi sugerida como modelo para exame de ingresso em uma universidade brasileira. Resultados da investigação realizada apontaram para a existência de diferentes formas e valores pelas quais os jovens traduzem o passado para o presente, bem como suas perspectivas de futuro.
\end{abstract}

Palavras-chave: consciência histórica; educação histórica; aprendizagem histórica.

${ }^{1}$ Doutora em História. Pós-doutorado em Didática da História. Professora de Metodologia e Prática de Ensino de História e do Programa de Pós-Graduação em Educação da Universidade Federal do Paraná. Coordenadora do Laboratório de Pesquisa em Educação Histórica. Universidade Federal do Paraná-UFPR, Brasil. e-mail: dolinha08@uol.com.br 


\begin{abstract}
According to Rüsen (2010), due to situations of practical life, decisions are made depending on values and the historical consciousness is a prerequisite to mediate values and reality. In fact, it works in a specific way of direction in practical life present situations, because it gathers past and present, giving perspectives of future to living realities, building moral values to a "temporal body". A qualitative investigation was done from these presuppositions (EISNER, 1998), with sixty Brazilian youngs (13 to 16 years old) of low and middle social classes. These were students from a public school of Curitiba city, Paraná State (Southern Brazil). They were asked to make a narrative from the following question: "Write to a young person like you about your reflexions on: Do altruism, the nonephemeral thought and difference still have a place in the contemporaneous world?". This question was chosen because it was an examination question to enter a Brazilian university. The results demonstrated the existence of different ways in which the youngest translate the past to the present, and also their perspectives for the future.
\end{abstract}

Keywords: historical consciousness; historical education; historical learning.

\title{
Introdução
}

As pesquisas que vêm sendo realizadas no âmbito do Laboratório de Pesquisa em Educação Histórica da Universidade Federal do Paraná, Brasil, têm procurado apontar algumas questões que envolvem a relação entre cultura, cultura histórica e cultura escolar, ou seja, tudo o que é produzido no âmbito das relações entre as mediações culturais e relacionado com os sujeitos no processo de escolarização, a história e a cultura da escola, isto é, os processos que envolvem a experiência histórica e concreta dos sujeitos, no interior dos processos de escolarização. (FORQUIN, 1993).

Um dos recortes principais das discussões encetadas pelos pesquisadores do LAPEDUH diz respeito à natureza e à especificidade da aprendizagem histórica. Nesse sentido, a proposta desse texto é realizar uma reflexão, tomando como referência a questão da aprendizagem histórica, pensada a partir do campo teórico da Educação Histórica, no sentido de apreender a especificidade dos processos cognitivos específicos da história, tendo como referência um diálogo entre o pensamento rüseniano e alguns fundamentos educacionais baseados no pensamento de Paulo Freire. 
É nesse contexto, e entendendo que, quando se fala de aprendizagem histórica, essa diz respeito à aprendizagem no contexto escolar e, portanto, envolve sujeitos e contextos históricos e culturais, que se insere a problemática que levou a essa reflexão: em que medida a cultura pode ser pensada como referência para a aprendizagem histórica. tomando-se como indicativos elementos da cognição histórica, a partir do pensamento rüseniano, e elementos do pensamento educacional de Paulo Freire.

\section{Histórico}

Desde o início do século XX, no Brasil, institui-se o debate sobre a necessidade de ruptura com perspectivas do ensino de História pautadas somente no estudo do passado. Esses debates foram fortemente influenciados pela difusão e repercussão das obras de John Dewey no Brasil ${ }^{2}$. Essa repercussão ocorreu no contexto de difusão das ideias do movimento da Escola Nova pelos educadores brasileiros, particularmente entre as décadas de 1930 e 1970. Propostas renovadoras para o ensino de História passam a ser defendidas, tanto em publicações destinadas à formação de professores como nas sucessivas reformas curriculares realizadas no país ${ }^{3}$. Foi no pensamento de J. Dewey que essas propostas se basearam para propor uma ruptura com o ensino de História baseado no estudo do passado pelo passado. Como afirma esse autor, se nós entendermos a história como o estudo dos fatos passados, é bem difícil legitimar sua presença nos programas escolares, porque

O passado é o passado e é preciso deixar os mortos enterrarem seus mortos. O presente e o futuro nos chamam com muita insistência para que nós nos permitamos mergulhar a criança num oceano de fatos desaparecidos para sempre. É preciso acima de tudo que consideremos a história como uma explicação das forças e das formas que se apresentam na vida social. Essa vida social é a atmosfera que nós respiramos; o presente e o passado se entrelaçam indissoluvelmente (DEWEY, 1913, p: 119).

Com sua preocupação em relacionar o ensino de História aos interesses da criança e da vida social, Dewey forneceria a orientação necessária ao

${ }^{2}$ Uma das obras de J. Dewey, L'école et L'enfant (Paris: Delachaux \& Niestlé, 1913), foi utilizada como referência por vários autores de manuais de Didática da História publicados no Brasil no período de 1935 a 1971.

${ }^{3}$ As principais Reformas Curriculares Brasileiras no período de 1930 a 1971 foram: Lei Francisco Campos, 1931; Lei Gustavo Capanema, 1942; Lei 4.024, 1961 e Lei 5.692, 1971. Após este ano, as reformas educacionais são realizadas no contexto do período pós-Ditadura Militar Brasileira, a partir de 1984 . 
rompimento com o estudo do passado pelo passado. Dessa forma, a relação presente/passado passou a ser instalada, definitivamente, como uma das principais e duradouras indicações para a metodologia do ensino de História no Brasil. Exemplo disso pode ser encontrado nos Parâmetros Curriculares Nacionais, onde se afirma que "É tarefa do professor criar situações de ensino para os alunos estabelecerem relações entre o presente e o passado". (PCNs, 1998, p.77).

Mantendo a tradição inaugurada por J. Dewey, pode-se afirmar que a preocupação em tomar o presente do aluno como referência para as relações com o passado passou a ser uma adoção inconteste entre os especialistas do ensino de História, inclusive servindo de base para fundamentar macroavaliações, como atesta a questão sugerida como padrão para a prova dissertativa de uma das maiores e mais importantes universidades públicas brasileiras - $O$ altruísmo, o pensamento não efêmero e a diferença ainda têm lugar no mundo contemporâneo? (Estadão EDU, março, 2011). Essa questão motivou a realização desse estudo exploratório, já que a relação orgânica entre as diferentes dimensões da cultura histórica - estética, política e cognitiva -, pode ser considerada como uma das preocupações de investigação, no quadro de referências teóricas que apontam as relações entre aprendizagem da história e formação da consciência histórica.

\section{Referencial teórico}

\section{Cultura e cultura histórica: primeiras aproximações conceituais entre Paulo Freire e Jörn Rüsen}

O conceito de cultura é um dos principais fundamentos da teoria da consciência histórica de Jörn Rüsen e da teoria da consciência crítica de Paulo Freire. Esses dois autores entendem a cultura como um processo integral de vida, de caráter social, que precisa ser compreendida numa perspectiva relacional, com ênfase na interdependência entre todos os aspectos da realidade social e na devida dinâmica da mudança social. Assim, a cultura não se situa como elemento absolutamente superestrutural, nem pode ser entendida como mero reflexo da infraestrutura, mas necessita ser apreendida nos e a partir de processos relacionais. A perspectiva conceitual que referencia a obra desses autores incorpora a cultura numa totalidade, como resultado da condição humana universal, como um conjunto ou produto da experiência humana, como um processo da tradição seletiva e como a ação humana na vida prática. Nesse sentido, entende-se a cultura como algo vivido em um momento e em um lugar; a cultura como produto histórico de um determinado período e sociedade e a 
cultura como seleção intencional da história da humanidade. Assim, pode-se falar em elementos da cultura referindo-se aos artefatos, ideias, signos e símbolos, às linguagens e tudo que permite e realiza as mediações dos e entre sujeitos, em relações sociais historicamente determinadas, onde estes sujeitos são produto e também produtores de cultura, constituindo-se enquanto categorias específicas como a cultura histórica e a cultura escolar.

Na perspectiva de Freire (1987) a cultura é o marco definidor do processo de hominização e é por meio dela que a humanidade se manifesta como existência, autodesvelando-se como história, explicitando-se pela consciência histórica. Nesse particular, no pensamento freiriano, "essa consciência histórica, objetivando-se reflexivamente, surpreende-se a si mesma, passa a dizer-se, torna-se consciência historiadora: o homem é levado a escrever a sua história" (FIORI, Apud Freire, 1987, p. 18. Aproximando-se claramente dessa perspectiva, Rüsen (1994) aponta a consciência histórica como uma realidade elementar e geral da explicação humana do mundo e de si mesmo, com um significado inquestionável prático para a vida, propondo que

.... da consciência histórica há somente um pequeno passo à cultura histórica. Se se examina o papel que tem a consciência histórica na vida de uma sociedade, aparece como uma contribuição cultural fundamentalmente específica que afeta e influi em quase todas as áreas da práxis da vida humana. Assim, a cultura histórica pode ser definida como a articulação prática e operante da consciência histórica na vida de uma sociedade. Como práxis da consciência tem a ver, fundamentalmente, com a subjetividade humana, como uma atividade da consciência, pela qual a subjetividade humana se realiza na prática, cria-se, por assim dizer. [...] A cultura histórica contempla as diferentes estratégias da investigação científicoacadêmica, da criação artística, da luta política pelo poder, da educação escolar e extraescolar, do ócio e de outros procedimentos da memória histórica pública. (RÜSEN, 1994p. 4).

A potencialidade categorial desse conceito de cultura remete também à possibilidade de se falar de uma cultura específica relacionada com os processos formativos da consciência histórica, qual seja, a chamada cultura escolar e cultura da escola. Na perspectiva adotada por Forquin (1993), a cultura escolar pode ser definida como o conjunto dos conteúdos cognitivos e simbólicos que, selecionados, organizados, normatizados, rotinizados, sob o efeito dos imperativos de didatização, constituem habitualmente o objeto de uma transmissão deliberada no contexto das escolas e da cultura da escola, sendo essa última a forma específica de realização da cultura escolar no interior da própria escola. 


\section{O método de conscientização de Paulo Freire e a formação da consciência histórica de Rüsen}

Em Rüsen (2001) são quatro tipos de consciência histórica: tradicional (a totalidade temporal é apresentada como continuidade dos modelos de vida e cultura do passado); exemplar (as experiências do passado são casos que representam e personificam regras gerais da mudança temporal e da conduta humana); crítica (permite formular pontos de vista históricos, por negação de outras posições); e genética (diferentes pontos de vista podem ser aceitos porque se articulam em uma perspectiva mais ampla de mudança temporal, e a vida social é vista em toda sua complexidade). Considerando que esse autor construiu sua tipologia, fundamentalmente, a partir do pensamento historiográfico (alemão), entende-se que a relação possível a partir do diálogo entre a cultura dos alunos e professores, a cultura histórica e a cultura escolar, permite uma apropriação original dessa tipologia. Isso porque pesquisas que vêm sendo realizadas no âmbito do LAPEDUH-UFPR-BR assim o têm demandado.

O educador Paulo Freire, ao estabelecer alguns princípios fundamentais do que chamou a Pedagogia do oprimido (1987), afirma uma tipologia da consciência relacionadas às visões de mundo dos educandos e educadores, dividida em três tipos: a consciência semitransitiva, a consciência transitiva ingênua e a consciência crítica.

Para Rüsen, o pensamento histórico acontece no processo temporal da vida humana. A história acontece como um processo temporal, ela insere temporalidade na vida humana. Mas esse processo acontece a posteriori porque, enquanto a pessoa está vivenciando a história em sua vida, ela não pode ser pensada ou considerada historicamente. Essa condição Rüsen chama de prépensamento histórico. É nesse nível que pode ser localizado o nível da chamada consciência semitransitiva de Paulo Freire, em que a realidade é percebida de forma a-histórica, e o sujeito se vê sem possibilidades da ação transformadora da vida prática. As visões fatalistas e subordinadas aos preceitos do senso comum dominante preenchem a mente humana e explicam as experiências do passado.

Em sua quase imersão na realidade, esta modalidade de consciência não consegue captar muitos dos desafios do contexto ou os percebe distorcidamente. Sua semi-intransitividade envolve uma certa obliteração que lhe é imposta pelas condições objetivas. [...] É que, nesse nível de quase imersão, não se verifica facilmente o que chamamos de "percepção estrutural" dos fatos, que implica a compreensão verdadeira da razão de ser dos mesmos. Desta forma, a explicação para os problemas se acha sempre fora da realidade, ora nos desígnios divinos, ora no destino [...] (FREIRE, 1976, p. 120). 
Esse nível de consciência, segundo Rüsen, pode ser considerado o primeiro nível reflexivo no qual acontece um pré-pensamento histórico e que é chamado hoje em dia de construção. Para ele, a maneira que ocorre essa construção pela cognição e argumentação conceitual é fortemente matizada pelas visões preconcebidas da história que existem na vida presente. Nesse nível, a história é um elemento real da vida social, uma condição ou circunstância cultural preestabelecida, sob a qual o pensamento histórico ocorre. O passado, presente nas condições da vida cultural, constrói o construtor porque a vida humana prática é guiada por convenções ou tradições pre-estabelecidas.

$\mathrm{Na}$ consciência transitiva ingênua de Paulo Freire, "a capacidade de captação se amplia e não apenas o que antes não era percebido passa a ser, mas também muito do que era entendido de uma certa forma o é agora de maneira diferente" (FREIRE, 1976, p. 123). Esse nível no qual se possui uma perspectiva histórica mais voltada para a contestação do passado, sem alternativas para o futuro, pode também ser considerado o nível da consciência prévia de Rüsen (2010b). Trata-se, para esse autor, do ponto de partida para a aprendizagem histórica, pois "a aprendizagem histórica começa com um "input" da experiência histórica na consciência histórica prévia dos estudantes (2010b, p. 23)".

Segundo Freire (1970), a passagem da consciência ingênua para a formação da consciência crítica exige um processo de explicitação, em que a injustiça se torne um percebido claro para a consciência, possibilitando aos sujeitos inserirem-se no processo histórico e fazendo com que eles se inscrevam na busca de sua afirmação. Ademais, afirma o autor, a consciência crítica possibilita a inscrição dos sujeitos na realidade para melhor conhecê-la e transformála, formando-o para enfrentar, ouvir e desvelar o mundo, procurando o encontro com o outro, estabelecendo um diálogo do qual resulta o saber: "os homens, desafiados pela dramaticidade da hora atual, se propõem a si mesmos como problema. Descobrem que sabem pouco de si [...] e se fazem problema eles mesmos. Indagam. Respondem, e suas respostas os levam a novas perguntas". (FREIRE, 1987, p. 29). Ele relaciona a sua concepção de consciência crítica com a construção de um senso histórico nas pessoas. Para Freire, a autoconsciência é já um passo para a construção da consciência crítica, como reproduz a fala de um trabalhador, em sua obra Pedagogia do oprimido: - "Não posso dizer que haja entendido todas as palavras que foram ditas aqui, mas uma coisa posso afirmar: cheguei a esse curso ingênuo e, ao descobrir-me ingênuo, comecei a tornar-me crítico. Esta descoberta, contudo, nem me faz fanático, nem me dá a sensação de desmonoramento" (FREIRE, 1987, p. 23).

Nesse conceito freiriano, cruzam-se duas tipologias da consciência histórica de Rüsen (2010a): a do tipo crítico e a do tipo genético. Segundo esse 
autor, na consciência crítica, "a história funciona como uma ferramenta com a qual se rompe, - "se destrói" -, se decifra a continuidade - para que perca seu poder como fonte de orientação para o presente". (RÜSEN, 2010a, p. 7). Ademais, completa o autor:

O pensamento histórico-crítico injeta elementos de argumentação crítica ao raciocínio moral. Põe em questão a moral apontando a relatividade cultural dos valores, que contrasta com a universalidade suposta e aparente, descobrindo os fatores da condição temporal que contrasta com uma validade atemporal falsa. Confronta as solicitações de validade com a evidência baseada na mudança temporal: o relativo poder das condições e consequências históricas. (RÜSEN, 2010a, p. 8).

A concepção de consciência histórica genética defendida por Rüsen (2010a) anuncia a formação da consciência histórica como um princípio do ensino de História, pautada numa racionalidade baseada num agir humano cuja referência é a dialética da vivência histórica, a partir de experiências individuais e coletivas. Para ele, é essa consciência histórica que dá à vida uma "concepção do curso do tempo", "trata do passado como experiência e revela o tecido da mudança temporal no qual estão amarradas as nossas vidas, bem como as experiências futuras para as quais se dirigem as mudanças". (RÜSEN, 2010a, p. 29). Essa concepção molda os valores morais a um "corpo temporal", transformando esses valores em "totalidades temporais", isto é, recupera a historicidade dos valores e a possibilidade dos sujeitos problematizarem a si próprios e procurarem respostas nas relações entre passado/presente/futuro, pois

[...] Permitimos que a história faça parte do passado, no entanto, ao mesmo tempo, lhe concedemos outro futuro. A mudança propriamente dita é que dá sentido à história. A mudança temporal se despojou de seu aspecto ameaçador e se transformou no caminho no qual estão abertas as opções para que a atividade humana crie um novo mundo. O futuro supera, excede efetivamente o passado em seu direito sobre o presente, um presente conceituado como uma intersecção, um nó intensamente temporal, uma transição dinâmica. (RÜSEN, 2001a, p. 9).

Essa possibilidade, como afirma Freire (1987), pode ser indicativa do reconhecimento da desumanização como realidade ontológica e histórica e também pode levar à pergunta se a humanização é possível.

\section{Implicações para a aprendizagem histórica}

No método freiriano, mesmo o patamar mais ingênuo da consciência do mundo exige do sujeito um distanciamento do seu mundo vivido, exercido 
pela problematização. Esse movimento da consciência permite que o sujeito se reconheça como alguém que antes se ignorava, o que o autor considera um passo para a concretização da ação intencional, apontando uma concepção de aprendizagem que exige um método de ensino que possibilite ao aprendiz o crescimento simultâneo da consciência do mundo e da consciência de si, sempre num processo de comprometimento uma com a outra.

Os pressupostos desse dar-se conta, em Freire, levam à ideia da "consciência para si”, que está relacionada com a auto-rreflexão e com a ideia do "ter a ver com". Observa-se que Freire valoriza a auto-rreflexão como o momento em que o sujeito percebe a sua relação com o mundo e no mundo. Mas, essa reflexão não se esgota numa posição estática face ao mundo, mas que se desenvolva na ação para a mudança de si e do seu mundo.

A consciência e o mundo não se estruturam sincronicamente numa estática consciência do mundo: visão e espetáculo. Essa estrutura funcionaliza-se diacronicamente numa história. A consciência humana busca comensurarse a si mesma num movimento que transgride, continuamente, todos os seus limites. Totalizando-se além de si mesma, nunca chega a totalizar-se inteiramente, pois sempre se transcende a si mesma. Não é a consciência vazia do mundo que se dinamiza, nem o mundo é simples projeção do movimento que a constitui como consciência humana. A consciência é consciência do mundo: o mundo e a consciência, juntos, como consciência do mundo, constituem-se dialeticamente num mesmo movimento - numa mesma história. Em outros termos, objetivar o mundo é historicizá-lo, humanizá-lo. (FIORI, 1987, p. 16-17).

Da mesma forma, para Rüsen (2010a, 2001), a consciência histórica relaciona "ser" (identidade) e "dever" (ação) em uma narrativa significativa que toma os acontecimentos do passado com o objetivo de dar identidade aos sujeitos a partir de suas experiências individuais e coletivas e de tornar inteligível o seu presente, conferindo uma expectativa futura a essa atividade atual. Portanto, a consciência histórica crítica e genética de Jörn Rüsen, assim como a consciência crítica, de Paulo Freire, têm uma "função prática" de dar identidade aos sujeitos e fornecer à realidade em que eles vivem uma dimensão temporal, uma orientação que pode guiar a ação, intencionalmente, por meio da mediação da memória histórica e, portanto, da cultura histórica.

No quadro de referências que articula as relações entre aprendizagem histórica e a formação da consciência histórica, entende-se que essa aprendizagem baseia-se numa estrada de mão dupla, construída a partir questões colocadas ao passado pelos sujeitos que vivem um determinado presente. Ademais, essa construção requer compromissos éticos com o presente, a partir 
do qual aqueles que aprendem identificam um passado de interesse e significância para todos os sujeitos, pois o seu "lugar social" é o lugar a partir do qual eles constroem suas experiências, orientações, interpretações e motivações, ao relacionarem presente, passado e futuro.

O "lugar social" é onde se encontram o lugar atual e o lugar do passado e sua finalidade principal é fornecer as condições e possibilidades do sentimento do "diz respeito a mim (a nós) e a noção de 'diz respeito a', enquanto categoria relevante para o ensino de história, significa que determinados contextos históricos, para o grupo, não são simplesmente 'coisa do passado', mas possuem uma relação existencial remanescente com o presente". (MARTINS, 2008, p.16). Nesse pressuposto está implícita a ideia do interesse individual ou em grupo, além da importante constatação de que o interesse é despertado porque há algum tipo de identificação dos sujeitos com a questão suscitada. Essa identificação pode provocar a busca de explicações, de respostas críticas, podendo chegar à construção de contextualizações metódicas do passado, contribuindo para a expansão das identidades, individuais ou coletivas. Justifica-se, assim, o fato de que a questão apresentada aos alunos possa ser examinada, seja no que "diz respeito a" suas vidas concretas, seja no seu reverso, ou naquilo que "não tem a ver comigo ou com os outros".

A perspectiva do "dizer respeito a", indicada por Martins, reforça o princípio da teoria da consciência histórica, pelo qual todo processo de aprendizagem deverá ter como ponto de partida a investigação de como o passado a ser estudado está presente na consciência histórica do aprendiz. De maneira concreta, esse princípio se realiza quando se investiga as narrativas do que Rüsen (2010b) chama de "consciência histórica prévia" dos sujeitos envolvidos no processo de ensino/aprendizagem para, a partir de uma sistemática categorização e análise, buscar, de forma coletiva e solidária, as questões que seriam significativas para a sua aprendizagem. As considerações desse autor também são levadas em conta quando afirma que "a consciência histórica transforma os valores morais em totalidades temporais: tradições, conceitos de desenvolvimento ou outras formas de compreensão do tempo" (2010,b p. 57), porque pode integrar "ser" e "dever" em uma narrativa significativa, cujo objetivo é fazer inteligível o presente e perspectivar o futuro, sempre a partir do presente. Assim, a consciência histórica atua em relação aos valores morais e à razão moral, no sentido de conferir a plausibilidade necessária que os valores necessitam para se tornarem aceitáveis na sua relação com a realidade.

Esses pressupostos justificam a possibilidade de análise das narrativas apresentadas pelos alunos, sistematizando as formas a partir das quais a consciência histórica procede ao conferir plausibilidade às suas experiências pre- 
sentes em relação com o passado e o futuro. O importante é que os "juízos de valor não apareçam independentes dos fatos históricos e que os processos de interpretação metodológica não figurem como um assunto meramente subjetivo, dos alunos e alunas" (RÜSEN, 2010b).

\section{Metodologia da investigação}

Trata-se de pesquisa de natureza qualitativa, realizada em 60 jovens alunos que frequentam do $6 .^{\circ}$ ao $9 .^{\circ}$ ano de uma escola pública localizada em um bairro afastado do centro da cidade de Curitiba-Paraná-Brasil. A escola tem cerca de 900 alunos e a escolha do campo de investigação e da população foi feita de forma aleatória, no conjunto de escolas públicas de Curitiba. O instrumento foi aplicado pelo professor de história da turma. Baseou-se em Eisner (1998), para quem a "indagação qualitativa" pode ser realizada com o objetivo de se melhorar a prática educativa. A partir desse autor, optou-se por realizar uma investigação focada na análise da consciência histórica prévia de jovens alunos, sendo que o instrumento pode ser balizado pela perspectiva da competência narrativa da consciência histórica. A análise e a interpretação dos dados também foram realizadas levando-se em consideração a qualidade da experiência ou situação social dos jovens alunos, buscando-se fazer falar as suas vozes.

Identificação social da população investigada

\begin{tabular}{|c|c|c|}
\hline IDADE & PROFISSÃO DO PAI & PROFISSÃO DA MÃE \\
\hline $\begin{array}{l}12 \text { anos: } 27 \\
13 \text { anos: } 20 \\
14 \text { anos: } 13\end{array}$ & $\begin{array}{l}\text { Vendedores: } 21 \text {; } \\
\text { Pedreiros: 02; Operários: } \\
\text { 07; Profissionais liberais } \\
\text { (dentista, marceneiro, } \\
\text { eletricista, caminhoneiro): } \\
\text { 11; Prestadores de serviço } \\
\text { (bombeiros, policiais, } \\
\text { motoristas etc.): } 19\end{array}$ & $\begin{array}{l}\text { Vendedoras: } 11 ; \\
\text { Donas de casa: } 22 ; \\
\text { Prestadoras de serviço } \\
\text { (professoras, secretária, } \\
\text { cabeleireira, costureira, } \\
\text { bancária etc.): } 27\end{array}$ \\
\hline
\end{tabular}

Observa-se que os pais dos jovens alunos pertencem à chamada classe "C", que hoje, no Brasil, agrupa a maior parte da população que vive nas médias e grandes cidades do país. 


\section{Principais resultados}

Como o instrumento proposto consistia na produção de uma narrativa a partir da questão: $O$ altruísmo, o pensamento não efêmero e a diferença ainda têm lugar no mundo contemporâneo?, pode-se, a partir do referencial teórico, analisar, principalmente, as ideias da consciência prévia dos jovens alunos, considerando que as temáticas sugeridas não fazem diretamente parte dos conteúdos históricos escolarizados, mas podem ser entendidas como motivadoras de juízos de valor realizados pelos alunos, no que se refere ao "dizer respeito a" ou "não dizer respeito a". Ademais, a utilização do marcador temporal "ainda" foi intencionalmente sugerida para potencializar a relação presente/passado/ futuro. Entre 60 instrumentos analisados, 4 não apresentaram nenhuma resposta e outros 56, tendo como referência os pressupostos teóricos do trabalho, foram categorizados a partir das seguintes perspectivas:

- dizem respeito a mim e ao outro baseadas na relação com o presente; - na relação presente e passado; - na relação presente e futuro; - na relação presente, passado e futuro.

1. Narrativas referenciadas apenas no presente e que "dizem respeito a mim e ao outro": 25 respostas

Algumas narrativas apresentaram matiz subjetivo mais forte que outras, sendo que a relação com a realidade mostrou-se um pouco precária, a partir da ênfase em um ou mais aspectos solicitados pela questão proposta. A ideia de efêmero apareceu quase sempre relacionada com amizade e amor, assim como a ideia de altruísmo.

[...] A palavra efêmero significa para mim um jovem que tem uma relação que se chama "Fica", dá uns beijos e vai embora e beija uma menina que nem conhece" [...] Daniel, 13.

Pouca amizade é como não ter nenhuma. As pessoas são muito injustas e impacientes, brigam por causa de nada, mas não podemos julgar todas as pessoas porque nem todas têm culpa dos atos dos outros [...] Bruno, 13.

Uma das ideias que mais apareceu, ligada ao presente e relacionada com os interesses significativos dos alunos, foi a de diferença. Em sua maioria, falavam sobre discriminação racial, modo de vida e diferença sexual. Somente uma narrativa apresentou a ideia de diferença relacionada com classe social. 
O mundo não aceita qualquer coisa. Isso é uma verdade. Várias coisas são diferentes. Os estilos de cada um são alguns exemplos. Mas a sociedade não aprova qualquer coisa. Uma prova são os homossexuais, não há espaço mais para tudo nesse mundo. Pessoas com pensamentos ou ideias diferentes não são ouvidas. As pessoas acreditam em uma só verdade, preferindo "rir" dessas outras pessoas, vindo então a rejeição. (João Lucas, 13).

As pessoas pensam que só porque elas são diferentes elas têm que discriminar os outros. Só porque a pessoa é rica não quer dizer que ela vai te discriminar e não é só porque a pessoa é pobre que ela vai discriminar os outros. Tem muitas pessoas que discriminam as outras pessoas pela cor. (Kaique, 14).

2. Narrativas que fazem relação presente e passado e que "dizem respeito a mim e ao outro": 10

A maioria das narrativas incluídas nessa categoria estabeleceu confrontos entre o passado e o presente na perspectiva da mudança para pior. Apenas duas narrativas apresentaram a relação presente e passado na perspectiva da continuidade e mudança.

Antigamente existiam pessoas que largavam de seus bens materiais para cuidar de outras pessoas com doenças, pobres etc... Hoje em dia existem poucas pessoas que largam de tudo para cuidar de outras pessoas. (Rafael, 14).

Talvez, mesmo com o fato de que o mundo está mudando ainda pode existir amor e respeito. As pessoas deviam amar o próximo. Mas, há tantas diferenças entre as pessoas que quase acho isso um tanto difícil de acontecer. Ninguém se importa com ninguém. Antigamente as pessoas eram diferentes do que as de hoje em dia, elas ajudavam os outros, até existiam alguns que viraram santos. Isso tudo só prova o quanto o mundo está cada vez pior em relação a isso. (Jean, 14).

No mundo contemporâneo existem várias coisas que nós achamos "surreais", como: o modo da pessoa se vestir, os seus gostos. Os tempos da moda antiga comparados com os tempos do presente, por exemplo, Elvis que foi o maior vendedor de discos na história da música, e até hoje ninguém conseguiu esse recorde. Hoje em 
dia também não se vê a paz que o mundo tinha antigamente, exemplo, não é mais seguro andar em ruas e temos que ter seguranças em lojas. (Odair, 14).

Hoje em dia tem casais velhos que se conheceram antigamente e até hoje estão juntos. Hoje em dia também há casais jovens e com vários tipos de gostos, por causa da modernidade, tem gays, lésbicas, heteros, etc... E não se pode ter preconceito, pois é a vida particular deles. (Karla, 12).

Nas narrativas incluídas nessa categoria (10), pode ser constatado que na relação com o passado, baseada somente na ideia de mudança ou na relação continuidade e mudança, os jovens alunos buscam alguma informação no passado para construírem a sua argumentação. Mesmo que ainda incipientes, as argumentações não estão baseadas somente no juízo de valor subjetivo. O "outro", encontrado nessas narrativas, varia desde um outro genérico, como "pessoas", "sociedade", até o outro mais específico, como homossexuais, casais idosos e jovens, jovens e até um personagem histórico como Elvis Presley.

3. Narrativas que fazem relação presente e futuro e "dizem respeito a mim e ao outro": 13

Apesar de serem em menor número, as narrativas que partem do presente e perspectivam o futuro, apresentam relações entre o que diz respeito a si mesmo, ao outro genérico (pessoas) e também ao mundo, no sentido do coletivo da humanidade. A partir da relação com o presente, entendido como o mundo em que se vive, os jovens alunos indicam suas opiniões com relação ao futuro da humanidade.

Hoje em dia as pessoas não pensam mais umas nas outras tanto quanto antes. Mas ainda existe bastante disso, as pessoas devem pensar mais nos outros, para que, com isso, o mundo torne-se um lugar melhor para viver. Isso influencia nos roubos etc. Os ladrões não querem saber se essa pessoa sofreu para comprar tal coisa. Eu acho que deveríamos pensar mais nos outros e não só em nós. (Leonardo, 15).

No mundo de hoje, não existem pessoas altruístas, que se importem com os outros mais do que consigo mesmo. Nesse mundo egoísta onde tudo gira em torno do dinheiro, será difícil existir uma pessoa altruísta. Hoje em dia tudo passa mais rápido, a tecnologia, os 
produtos, são sempre passageiros, um sempre entra no lugar do outro. Os amigos que parecem eternos se tornam passageiros, e também os namoros e os casamentos etc. A diferença existe sim, mas em cada pessoa porque a pessoa escolhe ser diferente com o outro, escolhe ou não ter preconceito com o próximo. Algum dia a diferença tem que acabar e as pessoas agirão normalmente uns com os outros, mesmo sendo gordo, magro, negro, branco, feio ou bonito. (Brian, 14).

Nos tempos em que vivemos o que prevalece é o egoísmo e o individualismo. Poucos são aqueles que dedicam seu tempo a algo ou alguém e isso está atrelado ao mundo contemporâneo que é cada vez mais competitivo. Com isso não são construídos relacionamentos com estruturas sólidas. Para melhorar o desenvolvimento da sociedade, é necessário pensar no coletivo e não apenas no indivíduo. Esse tipo de comportamento está cada vez mais escasso em nosso dia a dia. Não significa pensar apenas nas outras pessoas e dedicar-se inteiramente a isso e sim inserir no cotidiano o altruísmo, criando melhores condições e estruturas para a sociedade e futuras gerações. (Débora, 15).

As narrativas que focam a relação presente e futuro apresentam maior articulação entre "o que diz respeito a mim e ao outro", considerando esse outro a partir de elementos mais próximos da realidade. A referência à sociedade contemporânea nos seus aspectos de competitividade e violência, a relação do efêmero com a presença da tecnologia e a inter-relação entre individual e coletivo, entendendo esse coletivo como algo relacionado à sociedade, são recorrências importantes a serem destacadas nessas narrativas.

4. Narrativas que fazem relação entre presente, passado e futuro e "dizem respeito a mim e ao outro": 8

A relação presente, passado e futuro que os jovens alunos apresentam em suas narrativas mostram duas tendências principais. A primeira é a de que o mundo não mudou do passado até hoje em dia e tende a continuar do mesmo jeito se "as pessoas" não o salvarem. A segunda é de que o mundo mudou em parte e vai continuar mudando, e isso vai depender da ação das pessoas no presente e no futuro.

Cada vez mais o mundo se autodestrói, com atos de racismos e muitos outros. No mundo não mais existem pessoas que ajudam o 
próximo, que preferem largar suas vidas, muitas vezes com a qualidade de vida muito boa. Hoje em dia as pessoas estão mais preocupadas com suas vidas ou com aquelas pessoas famosas da televisão. O mundo precisa de ajuda. (Gustavo, 14).

O mundo não mudou muito. Ainda existem várias pessoas que falam mal da vida dos outros e que não se preocupam só com suas vidas. As coisas do tempo passado eram melhores, não ótimas, mas as pessoas viviam sem muita violência. O mundo para o jovem vai ser pior. Como estará quando tivermos nossos filhos e netos? Como eles irão conseguir sobreviver num mundo como o nosso? Essa é a dúvida. (Geovanna, 14).

Tem muitas pessoas que são contra os gays e as lésbicas e até batem nas pessoas porque não aceitam a diferença. Um caso atual é o da menina que apanhou de suas colegas só porque a chapinha do cabelo estava errada. Mas já teve muitas pessoas boas nesse mundo, como aquela senhora, dona Zilda Arns, que foi ajudar as pessoas no Haiti e aconteceu um terremoto que matou ela e mais da metade da cidade. E tem os que estão no meio termo, que dizem que vão arrumar hospitais e, quando eleitos, não fazem nada e não sabem o que fazer com o dinheiro do país. (Arnaldo, 13)

Nosso mundo mudou e continua mudando a cada segundo. Não existe [m] como antes, o amor ao próximo, a compaixão, a preocupação com o outro. Você largaria tudo para ser solidário? Não! Não tem nem como. Isso não existe mais, cada um pensa só em si mesmo. E, com certeza, tem muita gente precisando de nós. O mundo está em nossas mãos, nós somos o futuro. Nossos pensamentos são passageiros, não duram, igual nossas opiniões. Nem sempre temos opiniões concretas, as modinhas mexem com a nossa cabeça e se não mudarmos com o mundo, seremos os caretas, ignorantes... Mas, lembre-se, tem muita gente precisando de nós. (Amanda, 13).

Além de construírem argumentos utilizando elementos da realidade passada e presente, como a referência à personagem da dona Zilda Arns, líder brasileira na prevenção da mortalidade infantil e que já foi indicada para o prêmio Nobel da paz, essas narrativas perspectivam o futuro, seja com certezas estabelecidas a partir da relação entre mudança ou não mudança, seja com dúvidas, como as da jovem Geovanna. No entanto, de modo geral, os jovens 
alunos atribuem a si as possibilidades de mudança, sendo que alguns, como Amanda, incluem-se num coletivo, ainda que indeterminado.

\section{Principais conclusões}

Apesar das propostas curriculares brasileiras enfatizarem que o ensino e a aprendizagem da história deveriam levar em conta a relação presente e passado, essa investigação mostrou que pelo menos metade dos 60 jovens alunos pesquisados ateve-se ao presente para construir sua narrativa. No entanto, mesmo presos ao presente, esses jovens conseguiram construir um diálogo entre eles próprios e o outro da realidade em que vivem. A outra metade dos jovens conseguiu relacionar o seu presente, seja com o passado, seja com o futuro, seja com ambos, expressando a sua consciência histórica a partir do pressuposto do dizer respeito a mim e ao outro como fator de transformação dos valores morais em totalidades temporais.

Pode ser que essa passagem do dizer respeito a mim, para o dizer respeito ao outro, tenha relação com o "lugar social" em que presente, passado e futuro se cruzem na vida desses jovens. Como foi evidenciado, trata-se de jovens pertencentes a um segmento economicamente menos favorecido da sociedade brasileira e com precário acesso aos bens culturais fora do espaço escolar. É a partir desse "lugar social" que eles interagem com a totalidade da realidade brasileira e mundial contemporânea e esse fato pode ter contribuído para que, mesmo quando se relacionando apenas ao presente, eles consigam construir argumentos contra problemas como preconceitos de toda ordem, contra a provisoriedade das relações humanas e a favor da solidariedade.

De modo geral, pode-se afirmar que, em suas narrativas, grande parte dos jovens alunos conseguiu integrar "ser" e "dever", expressando possibilidades da consciência histórica de transformar valores morais em alguma forma de totalidade temporal, seja relacionando presente e passado, presente e futuro, presente/passado/futuro, a partir de elementos concretos de sua realidade. Mesmo que crivadas pelo subjetivismo do "diz respeito a mim" (salvar o mundo, por ex.), a relação com o outro do presente, do passado e do futuro esteve presente nas narrativas analisadas. Nesse sentido, acredita-se que esses dois pressupostos: - "dizer respeito a mim e ao outro" e "transformar valores morais em alguma totalidade temporal" e em suas narrativas, podem ser o ponto de partida para uma hipótese ontogenética relativa à consciência moral, como possibilidade para a análise da consciência histórica de jovens brasileiros. 


\section{REFERÊNCIAS}

BRASIL. SECRETARIA DE EDUCAÇÃO FUNDAMENTAL. Parâmetros curriculares nacionais: História. Secretaria de Educação Fundamental. Brasília: MEC/SEF, 1998.

DEWEY, J. L'école et L'enfant. Paris: Delachaux \& Niestlé, 1913.

EISNER, Elliot W. El ojo ilustrado. Indagación cualitativa y mejora de la práctica educativa. Barcelona: Paidós, 1998.

FIORI, Hernán Maria. Prefacio. In: FREIRE, Paulo. Pedagogia do Oprimido. Rio de Janeiro: Paz e Terra, 1987.

FORQUIN, Jean Claude. Escola e cultura.As bases sociais e epistemológicas do conhecimento escolar. Porto Alegre: Artes Médicas, 1993.

FREIRE, Paulo. Ação cultural para a liberdade. Rio de Janeiro: Paz e Terra, 1976.

FREIRE, Paulo. Pedagogia do Oprimido.Rio de Janeiro: Paz e Terra, 1987.

MARTINS, Estevão de Rezende. A exemplaridade da História: práticas e vivências do ensino. In: MARTINS, I. C.; GOHL, J. W. História e Historiografia Brasileira. COLÓQUIO NACIONAL DE HISTÓRIA E HISTORIOGRAFIA NO VALE DO IGUAÇU, 3, União da Vitória, 2008. Anais... União da Vitória, 2008. p. 13-21.

O ESTADO DE SÃO PAULO. EDU-Estadão. Suplemento Especial do Jornal $O$ Estado de São Paulo. São Paulo: Editora O Estado de São Paulo, 31 de março de 2011.

RÜSEN, Jörn. Que es la cultura histórica?: Reflexiones sobre una nueva manera de abordar la historia. Tradução: F. Sánchez Costa e Ib Schumacher. Original em: FÜSSMANN, K.; GRÜTTER, H.T.; RÜSEN, J. (eds). Historiche Faszination, GeschichtsKultur Heute. Keulen, Weimar and Wenen: Böhlau, 1994, pp.3-26. Disponível em www.culturahistorica.es. Acesso em 10.09.2010.

RÜSEN, Jörn. Razão Histórica. Teoria da História: os fundamentos da ciência histórica. Brasília: UnB, 2001. 
RÜSEN, Jörn. O desenvolvimento da competência narrativa na aprendizagem histórica: uma hipótese ontogenética relativa à consciência moral. In: SCHMIDT, M. A.; BARCA, I.; MARTINS, E. R. (Orgs.). Jörn Rüsen e o ensino de História. Curitiba: Ed. UFPR, 2010a. p. 51-78.

. Forming Historical Consciousness - Towards a Humanistic History Didacts. Transcript., 1-29, 28 May, 2010b

. Narrativa histórica: fundamentos, tipo, razão. In: SCHMIDT, M. A.; BARCA, I.; MARTINS, E. R. (Orgs.). Jörn Rüsen e o ensino de História. Curitiba: Ed. UFPR, 2010b, p. 93-108.

. O livro didático ideal. In: SCHMIDT, M. A.; BARCA, I.; MARTINS, E. R. (Orgs.). Jörn Rüsen e o ensino de História. Curitiba: Ed. UFPR, 2010c. p. $109-128$.

SCHMIDT, M. A.; BARCA, I.; MARTINS, E. R. (Orgs.). Jörn Rüsen e o ensino de História. Curitiba: Ed. UFPR, 2010.

Texto recebido em 20 de março de 2011.

Texto aprovado em 14 de setembro de 2011. 
